Review Article

\title{
“There's No Place Like Home”: A Scoping Review on the Impact of Homelike Residential Care Models on Resident-, Family-, and Staff-Related Outcomes
}

\author{
Dietmar Ausserhofer PhD, RN ${ }^{\mathrm{a}, \mathrm{b}, *}$, Mieke Deschodt PhD, $\mathrm{RN}^{\mathrm{c}}$, \\ Sabina De Geest PhD, $\mathrm{RN}^{\mathrm{b}, \mathrm{c}}$, Theo van Achterberg PhD, $\mathrm{RN}^{\mathrm{c}}$, Gabriele Meyer PhD, $\mathrm{RN}^{\mathrm{d}}$, \\ Hilde Verbeek $\mathrm{PhD}^{\mathrm{e}}$, Ingeborg Strømseng Sjetne $\mathrm{PhD}, \mathrm{RN}^{\mathrm{f}}$, \\ Iwona Malinowska-Lipień $\mathrm{PhD}, \mathrm{RN}^{\mathrm{g}}$, Peter Griffiths $\mathrm{PhD}, \mathrm{RN}^{\mathrm{h}}$, Wilfried Schlüter $\mathrm{PhD}^{\mathrm{i}}$, \\ Moriah Ellen MBA, PhD ${ }^{\mathrm{j}, k, 1}$, Sandra Engberg PhD, $\mathrm{RN}^{\mathrm{b}, \mathrm{m}}$ \\ ${ }^{a}$ College of Health-Care Professions Claudiana, Bozen, Italy \\ ${ }^{\mathrm{b}}$ Institute of Nursing Science, University of Basel, Basel, Switzerland \\ ${ }^{\mathrm{c}}$ KU Leuven, Department of Public Health and Primary Care, Academic Centre for Nursing and Midwifery, Leuven, Belgium \\ ${ }^{\mathrm{d}}$ Martin Luther University Halle-Wittenberg, Halle (Saale), Germany \\ ${ }^{\mathrm{e}}$ Maastricht University, CAPHRI School for Public Health and Primary Care, Department of Health Services Research, Maastricht, Netherlands \\ ${ }^{\mathrm{f}}$ The Knowledge Centre in Norwegian Institute of Public Health, Oslo, Norway \\ g Jagiellonian University, Krakow, Poland \\ ${ }^{\mathrm{h}}$ National Institute of Health Research Collaboration for Leadership in Applied Health Research and Care (Wessex), University of Southampton, \\ Southampton, United Kingdom \\ ${ }^{\mathrm{i}}$ European Association for Directors and Providers of Long-Term Care Services for the Elderly, Berlin, Germany \\ $\mathrm{j}$ Jerusalem College of Technology, Jerusalem, Israel \\ ${ }^{\mathrm{k}}$ The Gertner Institute for Epidemiology and Health Policy Research, Tel Aviv, Israel \\ ${ }^{1}$ McMaster University, Ontario, Hamilton, Canada \\ ${ }^{\mathrm{m}}$ School of Nursing, University of Pittsburgh, Pittsburgh, PA
}

\section{Keywords:}

Long-term care

homelike

small-scale

residential facilities

scoping review

\begin{abstract}
A B S T R A C T
Background: There is increasing emphasis on promoting "homelike" residential care models enabling care-dependent people to continue living in a self-determined manner. Yet, little is known about the outcomes of homelike residential care models.

Purpose: We aimed to (1) identify homelike residential care models for older care-dependent people with and without dementia, and (2) explore the impact of these models on resident-, family-, and staff-related outcomes. Design and Methods: We applied a scoping review method and conducted a comprehensive literature search in PubMed, Embase, and CINAHL in May 2015.

Results: We included 14 studies, reported in 21 articles. Studies were conducted between 1994 and 2014, most using a quasi-experimental design and comparing the Eden Alternative $(n=5)$, nondementiaspecific small houses (eg Green House homes) $(n=2)$, and dementia-specific small houses $(n=7)$ with usual care in traditional nursing homes. The studies revealed evidence of benefit related to physical functioning of residents living in dementia-specific small houses and satisfaction with care of residents living in nondementia-specific small houses compared with those living in traditional nursing homes. We did not find other significant benefits related to physical and psychosocial outcomes of residents, or in family- and staff-related outcomes.

Implications: The current evidence on homelike residential care models is limited. Comparativeeffectiveness research building on a clear theoretical framework and/or logic model and including a standardized set of resident-, family-, and staff-related outcomes, as well as cost evaluation, is needed to provide a stronger evidence base to justify the uptake of more homelike residential care models.
\end{abstract}

(c) 2016 AMDA - The Society for Post-Acute and Long-Term Care Medicine.
The authors declare no conflicts of interest.

* Address correspondence to Dietmar Ausserhofer, PhD, RN, Institute of Nursing Science, University of Basel, Bernoullistrasse 28, 4056 Basel, Switzerland.
E-mail address: dietmar.ausserhofer@unibas.ch (D. Ausserhofer). 
Health care systems worldwide are facing challenges in providing long-term care for an increasing population of older caredependent people with complex health needs, including multiple chronic diseases and functional and/or cognitive impairment. ${ }^{1}$ Between 2000 and 2013, in Organisation for Economic Co-operation and Development (OECD) countries, the average proportion of older care-dependent people receiving long-term care increased from $1.9 \%$ to $2.3 \%$. By 2050 , the percentage of the population older than 80 is expected to have risen from $4 \%$ to $10 \%$, linked to a projected increase in the prevalence of people living with dementia from 14.5 to 22.5 per 1000 population by $2035 .^{2}$ Consequently, the average proportion of gross domestic product spent on long-term care is projected to increase, such as from $2.0 \%$ to $3.6 \%$ between 2015 and 2060 in European countries. ${ }^{3}$ Most care-dependent people are cared for in their own homes by informal caregivers. ${ }^{4}$ Yet, approximately one-fifth receive care in residential care facilities, such as nursing homes (NHs), and by 2060, this population is estimated to nearly triple (from 2.9 to 8.3 million) in OECD countries. $^{4}$

NHs provide 24-hour-a-day nursing care for persons who are typically physically and/or cognitively impaired. ${ }^{5}$ The quality of care and quality of life in NHs has been a long-standing concern of consumers, care providers, and policy makers. ${ }^{6,7}$ An increasing body of evidence shows that $\mathrm{NH}$ residents commonly experience preventable negative outcomes (eg, adverse drug events, pressure ulcers, falls with injuries, physical and pharmacological restraint use, delirium, and elder abuse) associated with higher morbidity and mortality. ${ }^{8-14}$

The World Health Organization, the International Association of Gerontology and Geriatrics, and the Institute of Medicine in the United States emphasize the pressing need for innovative care models to improve the quality of care in NHs. There is an urgent need for residential care models that are "fit for the future" (eg, to transform NHs into more "homelike environments") and enable care-dependent people to continue living in a self-determined manner. ${ }^{15}$

A "model of care" is a multifaceted concept that broadly defines the way health services are delivered, outlining best practice care delivery through the application of a set of service principles across identified clinical streams and flow continuums. ${ }^{16}$ In the United States, the Green House and Eden Alternative are examples of residential care models, designed to look and feel like a home environment that returns control, dignity, and a sense of well-being to care-dependent people, while providing high-quality, personalized care. ${ }^{17,18}$ Indeed, over the years there has been greater emphasis to promote Green House homes, with currently more than 260 homes in 32 states open or under development. ${ }^{19}$ In Europe, there is an increasing emphasis on providing residential care for older people with dementia in small-scale living arrangements. In their literature review, Verbeek et $\mathrm{al}^{20}$ described the types and care characteristics of such small-scale and homelike environments, but did not examine outcomes.

Although we identified a recently published review on culture change in $\mathrm{NHs}$, we were unable to identify any published review that included a synthesis of research findings related to outcomes of small-scale homelike residential facilities. ${ }^{21}$ Yet such evidence is necessary to inform health policy makers, NH providers, and consumers about the potential benefit of fostering small-scale homelike residential facilities instead of traditional $\mathrm{NHs}$. We therefore conducted a scoping review to (1) identify homelike residential care models for older care-dependent people with and without dementia, and (2) explore the evidence about the impact of these care models on resident-, family-, and staff-related outcomes.

\section{Methods}

Design

To map and summarize the existing literature on homelike residential care models, a scoping review was conducted based on the framework outlined by Arksey and O'Malley. ${ }^{22}$ The aim of a scoping review is "summarizing a range of evidence in order to convey the breadth and depth of a field." ${ }^{23}$ Some key differences from a systematic literature review include formulating broad research aims (ie, no narrowly focused question), developing and refining selection criteria for papers during the review process (ie, post hoc instead of a priori), and omitting critical appraisal of risk of bias of the included studies. $^{22,24-26}$

\section{Study Identification}

A comprehensive literature search on homelike residential care models was conducted in May 2015 by 2 authors (SE and DA) using the PubMed, Embase, and CINAHL databases. A combination of Medical Subject Heading [MeSH] terms and free text terms was used in the search string: "Small-scale housing" [Keyword], "Home-like" [Keyword], "Shared housing arrangements" [Keyword], "Green House" [Keyword], "Eden Alternative" [Keyword], "Homes for aged" [Keyword], "Residential facilities"[MeSH], "nursing homes"[MeSH], "Family caregivers" [Keyword], and "Long-term care" [MeSH]. The search was limited to articles in English and included residents aged $65+$, without applying restrictions for publication date. The reference lists of potentially relevant studies were hand-searched for additional references.

\section{Study Selection}

Two researchers (SE and DA) screened the titles and abstracts based on the following predefined inclusion criteria: (1) quantitative (interventional and observational) studies, (2) published in a peerreviewed journal, (3) aims explicitly addressing homelike residential care models (settings designed specifically to resemble homelike environment, including small-scale units or houses), and (4) studies describing at least one resident-, family-, or staff-related outcome.

Because a priori defining strict selection criteria is not suitable for scoping reviews with broad research questions, the initial criteria were further refined during the study selection process. Studies were excluded if they investigated only one specific intervention to achieve cultural change in traditional NHs (eg, "relaxing music at mealtime") and if they did not perform any comparative analysis (eg, pre-post comparison or comparison with traditional $\mathrm{NH}$ care settings). Studies exploring the effect of homelike environments on staffing and skill mix levels only, and those examining resident-, family-, or staffrelated outcomes only in traditional $\mathrm{NH}$ settings were excluded. If the same findings were reported in more than one article from the same study, we included the most recent article.

\section{Data Charting}

Data from the included studies were extracted and summarized by one reviewer (SE) and checked for accuracy by a second reviewer (DA). The extracted data included study design, setting, and sample; purpose or aims; type of residential care model; and outcome variables and their measurement (Table 1, See Supplementary data). To synthesize and report meaningful findings, the heterogeneous outcomes and measures were categorized and summarized by type of setting: (1) Eden Alternative; (2) small, homelike settings not focusing specifically on residents with dementia (included Green House settings); 
and (3) small, homelike settings specifically designed for residents with dementia. In absence of a conceptual framework or core outcome set, outcomes were classified within 3 clusters: resident-, family-, and staff-related outcomes (Tables 2, 3, and 4). Resident-related outcomes were included only if they were reported in more than one study. Given the small number of studies examining outcomes for family and professional caregivers, we included outcomes that were measured in only one study. For each outcome, findings were classified as significant, nonsignificant, or mixed based on the main findings (group by time effects in repeated measures analyses and overall group comparisons). Findings were classified as mixed if there were significant differences (1) in relation to only one but not both comparison traditional NHs (ie, in studies in which there were 2 comparison traditional NHs), (2) in some but not all of the domains measured for an outcome, or (3) at some but not all time points that were compared.

\section{Findings}

\section{Study Selection}

Fourteen studies (corresponding to 21 articles), related to homelike care models' effects on resident-, family-, or staff-related outcomes, were included. The studied models of care were described as the Eden Alternative $(n=5)$, small group houses not specifically for persons with dementia $(\mathrm{n}=2)$, and various types of small-scale living arrangements for individuals with dementia $(n=7)$. The Eden Alternative is "a set of principles overlaid on existing NHs to flatten hierarchies, invest decision-making in residents and frontline staff, and normalize $\mathrm{NH}$ life, address psychosocial problems of residents, such as loneliness, boredom, helplessness, and lack of meaning."27(p832) Plants, animals, and contact with children are incorporated into the environment to create more homelike settings. One of the 2 studies of nondementia-specific small group houses examined outcomes for residents at Green House. This setting differs from a traditional $\mathrm{NH}$ in terms of facility size, interior design, organizational structure, staffing patterns, and methods of delivering skilled professional services. Green House homes are self-contained dwellings for 7 to 10 people needing $\mathrm{NH}$ levels of care. The physical environment offers residents opportunities for privacy and participation in community life with a residential-style kitchen where meals are prepared on site, a dining area with a communal dining table, a living room with fireplace, a sunroom, and accessible patio and outdoor space. In the Green House, frontline care staff members, who are Certified Nursing Assistants assigned to a single Green House, have broad roles, including cooking, housekeeping, personal laundry, personal care of residents, implementation of care plans, and assisting residents to spend time according to their preferences. ${ }^{28}$

The small-scale living arrangements for care-dependent people with dementia were all examined in European studies, yet varied by care concepts and characteristics. ${ }^{29-41}$ Most were separate houses or apartments with one study investigating household units within a traditional $\mathrm{NH}$. They also varied in relation to the number of residents with most housing 6 to 12 residents. In 6 of 7 studies of small-scale living facilities for people with dementia, houses that are designed to resemble a typical home with a maximum of 8 residents per house were examined. ${ }^{29-41}$ Residents, family, and a small, fixed team of staff performing multiple tasks including medical and personal care, organized activities and domestic tasks for one household. Activities center on daily life and meals are prepared in and by the household. For instance, Wolf-Ostermann et $\mathrm{al}^{41}$ investigated shared-housing arrangements for people with dementia living in large apartments in mostly urban settings, served by at least one community care service and being completely disconnected from traditional NHs. In contrast, Nakanishi et $\mathrm{al}^{42}$ investigated group-living units within traditional NHs, where frail older people lived in single-rooms. These group-living units were characterized by a common area, such as a dining room, for interaction among residents and stable staff assignments. Although the average number of residents per unit (average of 24 residents) was reported to be lower than in traditional $\mathrm{NH}$ units, compared with the other 6 studies it was relatively high (Table 1, See Supplementary data).

\section{Study Setting and Design}

Half of the 14 studies were conducted in the United States, 1 in Japan, and the remaining 6 in European countries, ie, the Netherlands, Belgium, Sweden, and Germany (Table 1, See Supplementary data). Six studies used a quasi-experimental design (ie, a pre-posttest with a usual $\mathrm{NH}$ care control group or a 1-group pre-posttest design). The 8 remaining studies used a prospective, retrospective, or cross-sectional observational design. In the quasi-experimental studies, outcomes were measured at baseline and at 6, 12, 18, and 24 months of followup. In the observational studies, outcomes were measured at baseline and $1,3,6$, and 12 months after residents moved to the small home settings. The retrospective observational study used data from preimplementation and 1 year postimplementation. In all comparative studies, the same outcomes were measured in traditional NH settings at an equivalent time point.

\section{Resident-Related Outcomes}

Thirteen studies examined resident-related outcomes, including physical (eg, activities of daily living [ADLs], accidental falls, pressure ulcers) and psychosocial (eg, cognitive status, mood, behavior, social activities, quality of life) outcomes (Table 2).

\section{Physical Outcomes}

Nine studies examined physical outcomes (Table 2). These outcomes were studied more often in Eden Alternative settings and nondementia-specific small group houses than in dementia-specific settings. The outcomes examined most often reflected some aspect of physical functioning. Three of the 5 studies focusing on Eden Alternative settings examined a physical functioning outcome and found no significant effects compared with traditional $\mathrm{NH}$ settings. ${ }^{18,43,44}$ One of 2 studies in nondementia-specific small houses reported that residents in the small, homelike settings had or maintained functioning better than those in traditional NHs. ${ }^{27}$ Kane et $\mathrm{al}^{45}$ reported mixed findings with no significant differences in selfreported ADLs or instrumental ADLs among residents in the homelike compared with 2 traditional NHs, whereas based on Minimum Data Set quality indicators, residents in the homelike setting had less decline in the late loss of ADLs than residents in the comparison NHs. In the 4 studies of small-scale living facilities for residents with dementia that examined some aspect of physical functioning, in 3 of the studies, functioning was significantly better in the small house residents than those in traditional NH settings, ${ }^{29,32,42}$ whereas there were no significant differences between settings in the fourth study. ${ }^{41}$ None of the other physical outcomes were examined in dementia-specific small, homelike facilities. Three studies examined nutrition-related outcomes, ${ }^{18,44,45}$ with one study in an Eden Alternative setting ${ }^{44}$ and one in nondementia-specific small houses ${ }^{45}$ reporting no significant differences in residents in homelike versus traditional NHs. In another Eden Alternative setting, Coleman et $\mathrm{al}^{18}$ reported more nutritional problems among residents in the homelike setting than in the traditional $\mathrm{NH}$, but without significant differences in weight or body mass index. Overall medication use was examined in 2 studies in Eden Alternative settings and 2 in nondementia-specific small houses. ${ }^{18,27,44,45}$ None of the studies reported significant differences in overall medication use compared with traditional $\mathrm{NH}$ settings. One 
Table 2

Summary of Findings on Resident-Related Outcomes

\begin{tabular}{|c|c|c|c|c|c|c|c|c|c|c|c|c|}
\hline \multirow[t]{2}{*}{ Outcome and Variables } & \multicolumn{4}{|c|}{ Eden Alternative, $\mathrm{n}=5$ Studies } & \multicolumn{4}{|c|}{$\begin{array}{l}\text { Small House: Not Dementia Specific, } \\
\mathrm{n}=2 \text { Studies }\end{array}$} & \multicolumn{4}{|c|}{$\begin{array}{l}\text { Small House: Dementia Specific, } \\
\mathrm{n}=7 \text { Studies }\end{array}$} \\
\hline & Studies* & $\begin{array}{l}\text { Significant } \\
\text { Effect }^{\dagger}\end{array}$ & $\begin{array}{l}\text { Mixed } \\
\text { Effect }^{\ddagger}\end{array}$ & $\begin{array}{l}\text { No Significant } \\
\text { Effect }\end{array}$ & Studies* & $\begin{array}{l}\text { Significant } \\
\text { Effect }^{\dagger}\end{array}$ & $\begin{array}{l}\text { Mixed } \\
\text { Effect }\end{array}$ & $\begin{array}{l}\text { No Significant } \\
\text { Effect }\end{array}$ & Studies* & $\begin{array}{l}\text { Significant } \\
\text { Effect }^{\dagger}\end{array}$ & $\begin{array}{l}\text { Mixed } \\
\text { Effect }\end{array}$ & $\begin{array}{l}\text { No Significant } \\
\text { Effect }\end{array}$ \\
\hline $\begin{array}{l}\text { Physical outcomes } \\
\text { Physical functioning: } \\
\text { - ADLs } \\
\text { - Functional competence } \\
\text { - PADLs } \\
\text { - IADLs } \\
\text { - ADL function } \\
\text { - Self-feeding } \\
\text { - Physical functioning } \\
\text { - Physical dependence }\end{array}$ & 3 & 0 & 0 & $3^{18,43,44}$ & 2 & $1^{27}$ & $1^{45}$ & 0 & 4 & $3^{29,32,42}$ & 0 & $1^{41}$ \\
\hline $\begin{array}{l}\text { Nutritional status: } \\
\text { - Body mass index } \\
\text { - Weight } \\
\text { - Nutritional problems } \\
\text { - Oral problems } \\
\text { - Weight loss } \\
\text { - Tube feedings } \\
\text { - Use of nutritional supplements }\end{array}$ & 2 & 0 & $1^{18}$ & $1^{44}$ & 1 & 0 & 0 & $1^{45}$ & 0 & 0 & 0 & 0 \\
\hline $\begin{array}{l}\text { Falls: } \\
\text { - Number of falls } \\
\text { - Fall rates }\end{array}$ & 2 & 0 & $2^{\text {[more falls: } 18,44]}$ & 0 & 1 & 0 & 0 & $1^{45}$ & 0 & 0 & 0 & 0 \\
\hline $\begin{array}{l}\text { Pressure ulcer: } \\
\text { - Pressure ulcers } \\
\text { - Stage } 4 \text { pressure ulcers }\end{array}$ & 1 & 0 & 0 & $1^{44}$ & 1 & 0 & 0 & $1^{45}$ & 0 & 0 & 0 & 0 \\
\hline $\begin{array}{l}\text { Overall medication use: } \\
\text { - Number of medications } \\
\bullet \geq 9 \text { medications/d } \\
\text { Psychosocial outcomes }\end{array}$ & 2 & 0 & 0 & $2^{18,44}$ & 2 & 0 & 0 & $2^{27,45}$ & 0 & 0 & 0 & 0 \\
\hline $\begin{array}{l}\text { Cognitive function: } \\
\text { - Cognition } \\
\text { - Cognitive impairment } \\
\text { - Recall ability } \\
\text { - Level of dementia }\end{array}$ & 3 & 0 & 0 & $3^{18,43,44}$ & 1 & 0 & 0 & $1^{45}$ & 4 & $1^{42}$ & 0 & $3^{29,32,41}$ \\
\hline $\begin{array}{l}\text { Social activities/social activation: } \\
\text { - Meaningful activities } \\
\text { - Little or no activity } \\
\text { - Daytime sleepiness } \\
\text { - Boredom } \\
\text { - Loneliness }\end{array}$ & 3 & $1^{44}$ & $1^{46}$ & $1^{43}$ & 1 & 0 & $1^{45}$ & 0 & 2 & $2^{32,36}$ & 0 & 0 \\
\hline $\begin{array}{l}\text { Mood: } \\
\text { - Depression } \\
\text { - Depressive symptoms } \\
\text { - Mood } \\
\text { - Negative affect } \\
\text { - Hopelessness } \\
\text { - Emotional blunting/labiality/motivation }\end{array}$ & 3 & $2^{46,48}$ & 0 & $1^{44}$ & 1 & 0 & $1^{45}$ & 0 & 3 & 0 & $1^{39}$ & $2^{29,36}$ \\
\hline $\begin{array}{l}\text { Resident quality of life (often } \\
\text { rated by staff or family): } \\
\text { - Resident-reported } \\
\text { - Staff-reported } \\
\text { - Family-reported }\end{array}$ & 0 & 0 & 0 & 0 & 1 & 0 & $1^{45}$ & 0 & 5 & $1^{42}$ & $3^{32,39,41}$ & $1^{35}$ \\
\hline
\end{tabular}

Family-reported 
Eden Alternative study ${ }^{44}$ and one nondementia-specific small house study ${ }^{45}$ found no differences in the prevalence of pressure ulcers compared with traditional NH settings. Of the 3 studies describing accidental falls as an outcome, both studies in Eden Alternative settings reported mixed findings with significantly more falls in the homelike environments during 1 of the 2 time frames measured. ${ }^{18,44}$ One of these studies also examined fall-related fractures and reported no significant difference by setting. ${ }^{44}$ Kane et $\mathrm{al}^{45}$ compared falls in nondementia-specific small houses (Green Houses) and traditional $\mathrm{NH}$ settings and reported no significant differences.

\section{Psychosocial Outcomes}

Twelve studies examined behavioral or quality of life outcomes (Table 2). Studies in all 3 types of settings examined aspects of cognitive function with most reporting no significant differences in homelike and traditional settings. ${ }^{18,29,32,41,43-45}$ In contrast, the Japanese study reported a significantly smaller deterioration in dementia (reported by direct care workers) between the first and second assessment (time frame not reported) in residents in the homelike dementia-specific units compared with those in the traditional $\mathrm{NH}$ units. ${ }^{42}$ Outcomes related to social activities/activation were measured in 3 Eden Alternative settings with significant beneficial effects relative to comparison $\mathrm{NHs}$ in one study, ${ }^{44}$ no difference in one study, ${ }^{43}$ and mixed findings in one study. ${ }^{46}$ Kane et $\mathrm{al}^{45}$ reported a positive effect of the Green House in relation to one comparison NH but not the other. In the 2 studies in dementia-specific settings, social activity/ activation outcomes were significantly better than in the comparison NHs. ${ }^{32,36}$ Outcomes related to mood were measured in 7 studies with significant benefits in the homelike settings relative to traditional NHs in 2 of the 3 Eden Alternative studies that examined this outcome. ${ }^{46,48}$ There was no significant difference in the third Eden Alternative study. ${ }^{44}$ Findings were mixed relative to traditional NHs in the one study of nondementia-specific small house settings ${ }^{45}$ and in 1 of the 3 dementia-specific settings that examined this outcome. ${ }^{39}$ There were no significant differences in the mood-related outcome relative to traditional $\mathrm{NH}$ residents in the other 2 dementia-specific settings that measured this outcome. ${ }^{29,36}$ Resident satisfaction was examined only in the 2 studies of nondementia-specific small group houses. In both studies, residents in homelike settings were significantly more satisfied than those in traditional $\mathrm{NH}$ settings. ${ }^{27,45}$ These 2 studies also compared self-rated health of the small house and traditional $\mathrm{NH}$ residents with no significant differences. ${ }^{27,45}$

The 10 studies investigating differences in residents' behavioral symptoms, prescription of psychotropic medications, and/or physical restraint use reported mixed findings. Two of the 5 studies examining outcomes in Eden Alternative settings and 1 of 2 studies in nondementia-specific small houses compared behavioral symptoms in these settings with traditional $\mathrm{NH}$ settings and did not find any significant difference between the settings. ${ }^{32,39,41,43,45}$ The other 2 studies examining this outcome reported mixed findings. In one of these studies, residents in the homelike setting had fewer dementiarelated behavioral symptoms than those in the traditional $\mathrm{NH}$ at one measurement time point but not the other. ${ }^{29}$ In the other study, there were significant group by time effects on one of the measures of behavioral symptoms but not the other. ${ }^{36}$ Both of the studies in Eden Alternative settings that examined physical restraint use reported significantly lower frequency of restraint use rates compared with traditional $\mathrm{NH}$ care. ${ }^{43,44}$ In 2 of the 3 studies in dementia-specific small house settings, there were no significant differences in restraint use, ${ }^{36,39}$ whereas in the third study, restraints were ordered for significantly fewer small house than traditional $\mathrm{NH}$ residents. ${ }^{32}$ Quality of life (resident-, family-, or staff-reported) was an outcome in 1 nondementia-specific ${ }^{45}$ and 5 dementia-specific small house studies. $^{32,35,39,41,42}$ Kane et al ${ }^{45}$ reported significantly better quality of 
Table 3

Summary of Findings on Family-Related Outcomes

\begin{tabular}{|c|c|c|c|c|c|c|c|c|c|c|c|c|}
\hline \multirow{2}{*}{$\begin{array}{l}\text { Outcome and } \\
\text { Variables }\end{array}$} & \multicolumn{4}{|c|}{ Eden Alternative } & \multicolumn{4}{|c|}{ Small House: Not Dementia Specific } & \multicolumn{4}{|c|}{ Small House: Dementia Specific } \\
\hline & Studies* & $\begin{array}{l}\text { Significant } \\
\text { Effect }^{\dagger}\end{array}$ & $\begin{array}{l}\text { Mixed } \\
\text { Effect }^{\dagger}\end{array}$ & $\begin{array}{l}\text { No Significant } \\
\text { Effect }\end{array}$ & Studies* & $\begin{array}{l}\text { Significant } \\
\text { Effect }\end{array}$ & $\begin{array}{l}\text { Mixed } \\
\text { Effect }^{\dagger}\end{array}$ & $\begin{array}{l}\text { No Significant } \\
\text { Effect }\end{array}$ & Studies* & $\begin{array}{l}\text { Significant } \\
\text { Effect }\end{array}$ & $\begin{array}{l}\text { Mixed } \\
\text { Effect }^{\dagger}\end{array}$ & $\begin{array}{l}\text { No Significant } \\
\text { Effect }\end{array}$ \\
\hline Satisfaction & 1 & $1^{47}$ & 0 & 1 & 1 & 0 & $1^{28}$ & 0 & 1 & $1^{37}$ & 0 & 0 \\
\hline Burden & 0 & 0 & 0 & 0 & 1 & 0 & 0 & $1^{28}$ & 3 & $1^{30}$ & 0 & $2^{34,35}$ \\
\hline $\begin{array}{l}\text { Assistance with } \\
\text { resident care }\end{array}$ & 0 & 0 & 0 & 0 & 1 & 0 & $1^{28}$ & 0 & 1 & 0 & 0 & $1^{35}$ \\
\hline $\begin{array}{l}\text { Contract with } \\
\text { resident }\end{array}$ & 0 & 0 & 0 & 0 & 0 & 0 & 0 & 0 & 2 & 0 & 0 & $2^{35,40}$ \\
\hline $\begin{array}{l}\text { Psychological } \\
\text { distress }\end{array}$ & 0 & 0 & 0 & 0 & 0 & 0 & 0 & 0 & 2 & $1^{31}$ & 0 & $1^{34}$ \\
\hline $\begin{array}{l}\text { Feeling of } \\
\text { caregiver } \\
\text { competence }\end{array}$ & 0 & 0 & 0 & 0 & 0 & 0 & 0 & 0 & 1 & 0 & 0 & $0^{34}$ \\
\hline $\begin{array}{l}\text { Interaction } \\
\text { with staff }\end{array}$ & 0 & 0 & 0 & 0 & 0 & 0 & 0 & 0 & 2 & $1^{40}$ & 0 & $1^{35}$ \\
\hline
\end{tabular}

*Number of studies that examined the variable.

†Significant in relation to only 1 or 2 comparison sites, on only a portion of domains measured, or not significant during all time frames compared.

life among residents in nondementia-specific small houses than residents in traditional $\mathrm{NH}$ settings for some but not all domains. Findings were mixed in the studies of dementia-specific small houses. Verbeek et $\mathrm{al}^{35}$ reported no significant group by time differences in staff and family ratings of residents' quality of life for residents living in small-scale dementia units and those living in traditional NH settings. Nakanishi et $\mathrm{al}^{42}$ reported that according to the staff, quality of life was higher for residents in homelike versus traditional $\mathrm{NH}$ units. In the remaining studies, findings were mixed, with significant improvements in some but not all domains measured, ${ }^{32,39,41}$ in relation to one comparison $\mathrm{NH}$ but not the other ${ }^{39,45}$ and/or better in some domains but worse in others compared with traditional NH settings. ${ }^{39}$

\section{Family-Related Outcomes}

Family-related outcomes were measured most frequently in the studies of dementia-specific small houses. Only 1 of the Eden Alternative studies and 1 of the 2 studies in nondementia-specific small homelike settings examined family-related outcomes (Table 3). Rosher and Robinson ${ }^{47}$ reported a significant improvement in total family satisfaction scores after the implementation of the Eden Alternative in an $\mathrm{NH}$. In the study in a nondementia-specific small house (Green House), Lum et $\mathrm{al}^{28}$ measured 5 domains of family satisfaction with resident care. Families of residents in the homelike setting reported significantly higher satisfaction in 3 domains (physical environment, autonomy, and health care) than families in both comparison NHs, whereas they reported significantly higher satisfaction in the other 2 domains (general amenities and family experience) than families from one but not the other $\mathrm{NH}$. Global satisfaction with the setting as a place to live and receive care was significantly greater in the homelike setting than in 1 of 2 comparison NHs. In this study, there were no significant differences in reported caregiver burden, whereas Green House families reported providing lower overall family assistance than those in one of the comparison NHs but not the other. ${ }^{28}$

Four studies (reported in 6 articles) compared family-related outcomes in dementia-specific homelike and traditional $\mathrm{NH}$ settings. Family satisfaction was measured in 1 study and was significantly higher in families of residents in the homelike settings than those of residents in traditional NHs in 1 study. ${ }^{37}$ Verbeek et al $^{35}$ compared families' reports of the amount of assistance they provided with resident care in small house and traditional $\mathrm{NH}$ settings and reported no significant differences. Three studies compared family burden in dementia-specific homelike and traditional NH settings. Andrén and Elmståhl $^{30}$ reported significant lower total burden in the families of residents of the small-scale dementia units compared with those of residents of traditional $\mathrm{NH}$ units. In contrast, te Boekhorst ${ }^{34}$ found no differences in informal caregiver burden in small-scale and traditional $\mathrm{NH}$ settings and Verbeek and colleagues ${ }^{35}$ found no group by time interaction effects in family burden in these 2 settings. Contact between the family and the resident after the institutionalization was investigated in 2 studies; neither of them found significant differences between homelike and traditional $\mathrm{NH}$ settings. ${ }^{35,40}$ te Boekhorst et $\mathrm{al}^{34}$ reported no significant difference for feeling of caregiver competence by setting. Family's interaction with staff was reported to be significantly better in homelike than in traditional $\mathrm{NHs}$ in one study, ${ }^{40}$ but not significantly different in the other study. ${ }^{35}$

\section{Staff-Related Outcomes}

Three studies examined staff-related outcomes in homelike and traditional NH settings (Table 4). Robinson and Rosher ${ }^{48}$ examined

Table 4

Summary of Findings on Staff-Related Outcomes

\begin{tabular}{|c|c|c|c|c|c|c|c|c|c|c|c|c|}
\hline \multirow{2}{*}{$\begin{array}{l}\text { Outcome and } \\
\text { Variables }\end{array}$} & \multicolumn{4}{|c|}{ Eden Alternative } & \multicolumn{4}{|c|}{ Small House: Not Dementia Specific } & \multicolumn{4}{|c|}{ Small House: Dementia Specific } \\
\hline & Studies* & $\begin{array}{l}\text { Significant } \\
\text { Effect }^{\dagger}\end{array}$ & $\begin{array}{l}\text { Mixed } \\
\text { Effect }^{\dagger}\end{array}$ & $\begin{array}{l}\text { No } \\
\text { Significant } \\
\text { Effect }\end{array}$ & Studies* & $\begin{array}{l}\text { Significant } \\
\text { Effect }\end{array}$ & $\begin{array}{l}\text { Mixed } \\
\text { Effect }^{\dagger}\end{array}$ & $\begin{array}{l}\text { No } \\
\text { Significant } \\
\text { Effect }\end{array}$ & Studies* & $\begin{array}{l}\text { Significant } \\
\text { Effect }\end{array}$ & $\begin{array}{l}\text { Mixed } \\
\text { Effect }^{\dagger}\end{array}$ & $\begin{array}{l}\text { No } \\
\text { Significant } \\
\text { Effect }\end{array}$ \\
\hline $\begin{array}{l}\text { Quality of work } \\
\text { life/job satisfaction }\end{array}$ & 1 & 0 & 0 & $1^{48}$ & 0 & 0 & 0 & 0 & 1 & 0 & 0 & $1^{35}$ \\
\hline Burnout & 0 & 0 & 0 & 0 & 0 & 0 & 0 & 0 & 1 & 0 & $1^{38}$ & 0 \\
\hline $\begin{array}{l}\text { Work-related mental } \\
\text { health problems }\end{array}$ & 0 & 0 & 0 & 0 & 0 & 0 & 0 & 0 & 1 & 0 & 0 & $1^{38}$ \\
\hline Motivation & 0 & 0 & 0 & 0 & 0 & 0 & 0 & 0 & 1 & 0 & 0 & $1^{35}$ \\
\hline
\end{tabular}

*Number of studies that examined the variable.

†Significant in relation to only 1 or 2 comparison sites, on only a portion of domains measured, or not significant during all time frames compared. 
staff-reported quality of work life before and 2 years after implementation of the Eden Alternative and reported that there was no significant difference, although only one-third of the original staff members were still employed at the postimplementation assessment. Verbeek et $\mathrm{al}^{35}$ reported that there was no significant difference in job satisfaction of staff working in dementia-specific homelike settings and those working in traditional NHs. Verbeek et $\mathrm{al}^{35}$ also measured staff motivation in the 2 types of facilities and reported no significant overall group differences. Staff-reported work-related mental health problems and burnout were investigated by de Rooij et al. ${ }^{38}$ Burnout was measured by 3 subscales (emotional exhaustion, depersonalization, and personal accomplishments) of the Dutch version of the Maslach Burnout Inventory. Staff working in dementia-specific homelike settings had significantly higher emotional exhaustion scores than staff working in traditional $\mathrm{NH}$ settings, but there were no significant differences in scores on the other 2 subscales. Moreover, there were no significant differences in work-related mental health problems among staff in the 2 types of settings. $^{38}$

\section{Discussion}

This scoping review revealed a limited number of studies comparing the effects of 3 types of homelike residential care models and traditional NHs with regard to resident-related outcomes, with very few studies investigating family- and staff-related outcomes. We found evidence that people with dementia living in dementia-specific small houses might benefit in terms of physical functioning. Caredependent people living in nondementia-specific small houses are more satisfied with care compared with residents in traditional NHs. We did not find any other consistently significant benefits related to physical and psychosocial outcomes for people living in any of the 3 homelike residential care models. There is limited research examining family- and staff-related outcomes in homelike environments compared with traditional NHs and we did not find evidence for better outcomes in homelike environments.

The small number of studies that investigated the effects of homelike residential care models demonstrated that the evaluation of such models has received little attention. The 3 types of homelike residential care models we identified in the literature (ie, the Eden Alternative, nondementia- and dementia-specific small-scale living arrangements) are complex interventions. ${ }^{49}$ They use different approaches to create a more homelike environment for residents, yet a more detailed description of the different intervention components is needed in future studies. In the Eden Alternative, an existing NH setting undergoes a cultural transformation through application of a wider set of principles and intervention components with limited environmental changes to make it more "homelike." In nondementia and dementiaspecific small living arrangements, care is usually provided in a homelike structure (eg, house, apartment) for a limited number of residents. Despite the differences in view of structural elements and the population cared for, a clear theoretical framework and/or logic model is lacking and our understanding of the benefits that should be expected and the negative effects that can be avoided by these homelike residential care models in comparison with traditional NHs is limited. Despite the increased emphasis on Green House in the United States and similar small-scale living facilities in European countries (eg, the Netherlands, Germany) methodologically sound studies building on a more solid theoretical ground and applying health services and comparative-effectiveness research methods are needed to provide evidence on why and how these models affect resident-, family-, and staff-related outcomes. Moreover, evaluating the economic impact of homelike residential care models in comparison with traditional NHs and in relationship to each other is crucial to inform long-term care and health policy decision-makers.
We found evidence that residents with dementia living in small houses seem to benefit with regard to physical functioning and resident in nondementia-specific small-scale living arrangements with regard to satisfaction with care compared with residents living in traditional NHs. This is not surprising given that the philosophical background of these models is based on reversing the "enforced dependency" that commonly occurs in a traditional $\mathrm{NH}^{50}$ Providing resident-centered care, which takes a holistic care approach and gives both physical and psychosocial care needs high priority, is the backbone of homelike residential care models. ${ }^{51}$ However, further studies are needed to gain a better understanding on possible differences between traditional $\mathrm{NHs}$ and homelike residential care facilities in providing safe and high-quality care. A major challenge in traditional NHs and more homelike residential care settings remains balancing competing priorities when addressing residents' physical and psychosocial care needs (eg, the prevention of falls and reducing physical and/or pharmacological restraint use). For instance, in 2 of 3 studies on the Eden Alternative, residents experienced more accidental falls than residents in traditional $\mathrm{NHs}$, yet fall-related injuries, investigated in 1 study, did not differ between the 2 settings. In the quasiexperimental study on the Eden Alternative, Coleman et $\mathrm{al}^{18}$ argued that this finding was related to the greater degree of cognitively and functionally impaired residents in traditional NHs, resulting in residents who were less mobile and less likely to fall. This is supported by Chang et al, ${ }^{44}$ who found that residents of household units had better physical functioning including mobility at baseline than those on traditional NH units. Although self-selection bias with residents with higher mobility being in the homelike environments is likely, it can be hypothesized that the greater emphasis on maximizing the independence of residents in homelike settings than in traditional NHs may also contribute to higher risk for falls and thus higher fall rates. Thus, guided by a theoretical framework, it will be crucial to develop a "core outcome set" (ie, a minimum set of outcome measures for future studies evaluating the existing and innovative new homelike residential care model). ${ }^{52}$ To our knowledge, new residential care models, such as "dementia villages" (see http://www.alzheimers.net/201308-07/dementia-village/), "ExtraCare Villages" (http://www.aston.ac. uk/lhs/research/centres-facilities/archa/extracare-project/), or "Green Care Farms" 53 might be promising approaches to improve resident-, family-, and staff-related outcomes. However, the characteristics and outcomes of these care models have not been examined. In preparing for future studies in this field applying Delphi or other consensusfinding techniques may help to reach consensus among residents, families, and experts on meaningful resident-, family-, and staffrelated outcomes and their measures that should be included in the evaluation of such models. $^{54}$

We did not find evidence that any of the 3 homelike residential models improved family- and staff-related outcomes, such as increased satisfaction with care or reduced caregiver burden/distress compared with traditional $\mathrm{NH}$ settings. Previous studies found that informal caregiver burden was a strong factor in seeking respite care and the institutionalization of care-dependent people in traditional NHs. ${ }^{5,56}$ As most informal caregivers visit their relative on a regular basis and are involved in care activities similar to those carried out when the care-dependent person was living at home (eg, feeding, grooming, managing money), ${ }^{57}$ informal caregiver burden might only slowly decrease over time in both homelike and traditional residential care facilities. $^{58}$

\section{Limitations}

We conducted a literature search in the 3 major electronic databases in the biomedical field, but did not search relevant psychology, behavioral, and social science databases (eg, PsycINFO) or the gray literature. We, therefore, might have missed relevant studies. The 
inclusion of nonexperimental and observational studies limits the ability to make causal inference about the outcomes measured. Last, for the purpose of this review, variables, particularly for resident outcomes, were clustered into categories to make broad comparisons across studies. The validity and reliability of this categorization was assessed only through face validity.

\section{Conclusion}

With this scoping review, we explored the impact of 3 different types of homelike residential care facilities (ie, Eden Alternative, nondementia- and dementia-specific small houses) on resident-, family-, and staff-related outcomes in comparison with traditional $\mathrm{NHs}$. We found a small number of heterogeneous studies highlighting a need for more high-quality research in this field. There was some evidence that people with dementia living in dementia-specific smallscale living arrangements benefit with regard to physical functioning and people living in nondementia-specific small houses benefit with regard to their satisfaction compared with traditional NHs. We found very few studies comparing family- and staff-related outcomes in homelike and traditional $\mathrm{NH}$ settings and no evidence that family(satisfaction, caregiver burden) and staff-related (higher job satisfaction) outcomes differed between homelike environments and traditional NH settings. Comparative-effectiveness research, including cost evaluation, is urgently needed to provide a stronger evidence base to justify the uptake of more homelike residential care models.

\section{Supplementary Data}

Supplementary data related to this article can be found online at http://dx.doi.org/10.1016/j.jamda.2016.03.009.

\section{References}

1. Robison J, Shugrue N, Porter M, et al. Transition from home care to nursing home: Unmet needs in a home- and community-based program for older adults. J Aging Soc Policy 2012;24:251-270.

2. OECD. Health at a Glance 2015. Paris: OECD Publishing; 2015.

3. European Commission, Economic Policy Committee. The 2012 Ageing Report: economic and budgetary projections for the EU-27 Member States (2010-2060), 2012. Available at: http://ec.europa.eu/economy_finance/ publications/european_economy/2012/pdf/ee-2012-2_en.pdf. Accessed April 15, 2016.

4. Colombo F, Llena-Nozal A, Mercier J, et al. OECD Health Policy Studies Help Wanted? Providing and Paying for Long-Term Care: Providing and Paying for Long-Term Care. Paris: OECD Publishing; 2011.

5. Sorensen SV, de Lissovoy G, Kunaprayoon D, et al. A taxonomy and economic consequences of nursing home falls. Drugs Aging 2006;23:251-262.

6. Comondore VR, Devereaux PJ, Zhou Q et al. Quality of care in for-profit and not-for-profit nursing homes: Systematic review and meta-analysis. BMJ 2009; 339:b2732.

7. Institute of Medicine. Improving the Quality of Long-Term Care. Washington (DC): The National Academies Press; 2001.

8. Handler SM, Wright RM, Ruby CM, et al. Epidemiology of medication-related adverse events in nursing homes. Am J Geriatr Pharmacother 2006;4:264-272.

9. Horn SD, Bender SA, Bergstrom N, et al. Description of the National Pressure Ulcer Long-Term Care Study. J Am Geriatr Soc 2002;50:1816-1825.

10. Rubenstein L. Falls in older people: Epidemiology, risk factors and strategies for prevention. Age Ageing 2006;35:ii37-ii41.

11. Möhler R, Richter T, Köpke S, Meyer G. Interventions for preventing and reducing the use of physical restraints in long-term geriatric care. Cochrane Database Syst Rev 2011;2:CD007546.

12. Boorsma M, Joling KJ, Frijters DH, et al. The prevalence, incidence and risk factors for delirium in Dutch nursing homes and residential care homes. Int J Geriatr Psychiatry 2012;27:709-715.

13. Cooper C, Selwood A, Livingston G. The prevalence of elder abuse and neglect: A systematic review. Age Ageing 2008;37:151-160.

14. Sears N, Baker GR, Barnsley J, et al. The incidence of adverse events among home care patients. Int J Oual Health Care 2013:25:16-28.

15. Tolson D, Rolland Y, Andrieu S, et al. International Association of Gerontology and Geriatrics: A global agenda for clinical research and quality of care in nursing homes. J Am Med Dir Assoc 2011;12:184-189.

16. Davidson P, Halcomb E, Hickman L, et al. Beyond the rhetoric: What do we mean by a 'model of care'? Aust J Adv Nurs 2006;23:47-55.
17. Sharkey SS, Hudak S, Horn SD, et al. Frontline caregiver daily practices: A comparison study of traditional nursing homes and the Green House project sites. J Am Geriatr Soc 2011;59:126-131.

18. Coleman MT, Looney S, O'Brien J, et al. The Eden Alternative: Findings after 1 year of implementation. J Gerontol A Biol Sci Med Sci 2002;57: M422-M427.

19. Robert Wood Johnson Foundation. The Green House ${ }^{\circledR}$ Project. A radical departure from traditional nursing homes. 2015. Available at: http://www.rwjf. org/en/how-we-work/grants/grantees/the-green-house-project.html. Accessed September 29, 2015.

20. Verbeek H, van Rossum E, Zwakhalen SM, et al. Small, homelike care environments for older people with dementia: A literature review. Int Psychogeriatr 2009;21:252-264.

21. Shier V, Khodyakov D, Cohen LW, et al. What does the evidence really say about culture change in nursing homes? Gerontologist 2014;54:S6-S16.

22. Arksey H, O'Malley L. Scoping studies: Towards a methodological framework Int J Soc Res Methodol 2005;8:19-32.

23. Armstrong R, Hall BJ, Doyle J, et al. Cochrane Update. 'Scoping the scope' of a Cochrane review. J Public Health (Oxf) 2011;33:147-150.

24. Levac D, Colquhoun H, O'Brien KK. Scoping studies: Advancing the methodology. Implement Sci 2010;5:69.

25. Kastner M, Tricco AC, Soobiah C, et al. What is the most appropriate knowledge synthesis method to conduct a review? Protocol for a scoping review. BMC Med Res Methodol 2012;12:114.

26. Daudt HM, van Mossel C, Scott SJ. Enhancing the scoping study methodology: A large, inter-professional team's experience with Arksey and O'Malley's framework. BMC Med Res Methodol 2013;13:48.

27. Molony SL, Evans LK, Jeon S, et al. Trajectories of at-homeness and health in usual care and small house nursing homes. Gerontologist 2011;51: 504-515.

28. Lum TY, Ph D, Kane RA, et al. Effects of Green House ${ }^{\circledR}$ nursing homes on residents' families. Health Care Financ Rev 2009;30(2):35-52.

29. Annerstedt L. An attempt to determine the impact of group living care in comparison to traditional long-term care on demented elderly patients. Aging Clin Exp Res 1994;6:372-380.

30. Andrén S, Elmståhl S. Former family carers' subjective experiences of burden: A comparison between group living and nursing home environments in one municipality in Sweden. Dementia 2002;1:241-254.

31. Smit D, te Boekhorst S, de Lange J, et al. The long-term effect of group living homes versus regular nursing homes for people with dementia on psychological distress of informal caregivers. Aging Ment Health 2011;15: 557-561.

32. te Boekhorst S, Depla MF, de Lange J, et al. The effects of group living homes on older people with dementia: A comparison with traditional nursing home care. Int J Geriatr Psychiatry 2009;24:970-978.

33. te Boekhorst S, Depla MF, Pot AM, et al. The ideals of group living homes for people with dementia: Do they practice what they preach? Int Psychogeriatr 2011;23:1526-1527.

34. te Boekhorst S, Pot AM, Depla M, et al. Group living homes for older people with dementia: The effects on psychological distress of informal caregivers. Aging Ment Health 2008;12:761-768.

35. Verbeek H, Zwakhalen SM, van Rossum E, et al. Dementia care redesigned: Effects of small-scale living facilities on residents, their family caregivers, and staff. J Am Med Dir Assoc 2010;11:662-670.

36. Verbeek H, Zwakhalen SM, van Rossum E, et al. Effects of small-scale, homelike facilities in dementia care on residents' behavior, and use of physical restraints and psychotropic drugs: A quasi-experimental study. Int Psychogeriatr 2014;26:657-668.

37. Verbeek H, Zwakhalen SM, van Rossum E, et al. Small-scale, homelike facilities in dementia care: A process evaluation into the experiences of family caregivers and nursing staff. Int J Nurs Stud 2012;49:21-29.

38. de Rooij AH, Luijkx KG, Declercq AG, et al. Professional caregivers' mental health problems and burnout in small-scale and traditional long term care settings for elderly people with dementia in the Netherlands and Belgium. J Am Med Dir Assoc 2012;13:486.e7-486.e11.

39. de Rooij AH, Luijkx KG, Schaafsma J, et al. Quality of life of residents with dementia in traditional versus small-scale long-term care settings: A quasiexperimental study. Int J Nurs Stud 2012;49:931-940.

40. de Rooij AH, Luijkx KG, Spruytte N, et al. Family caregiver perspectives on social relations of elderly residents with dementia in small-scale versus traditional long-term care settings in the Netherlands and Belgium. J Clin Nurs 2012;21:3106-3116.

41. Wolf-Ostermann K, Worch A, Fischer T, et al. Health outcomes and quality of life of residents of shared-housing arrangements compared to residents of special care units: Results of the Berlin DeWeGE-study. J Clin Nurs 2012;21: 3047-3060.

42. Nakanishi M, Nakashima T, Sawamura K. Quality of life of residents with dementia in a group-living situation: An approach to creating small, homelike environments in traditional nursing homes in Japan. Nihon Koshu Eisei Zasshi 2012;59:3-10.

43. Hinman MR, Heyl DM. Influence of the Eden Alternative ${ }^{\mathrm{TM}}$ on the functional status of nursing home residents. Phys Occup Ther Geriatr 2002;20:1-20.

44. Chang YP, Li J, Porock D. The effect on nursing home resident outcomes of creating a household within a traditional structure. J Am Med Dir Assoc 2013; 14:293-299. 
D. Ausserhofer et al. / JAMDA xxx (2016) 1-9

45. Kane RA, Lum TY, Cutler LJ, et al. Resident outcomes in small-house nursing homes: A longitudinal evaluation of the initial green house program. J Am Geriatr Soc 2007;55:832-839.

46. Bergman-Evans B. Beyond the basics. Effects of the Eden Alternative model on quality of life issues. J Gerontol Nurs 2004;30:27-34.

47. Rosher RB, Robinson S. Impact of the Eden Alternative on family satisfaction. J Am Med Dir Assoc 2005;6:189-193.

48. Robinson SB, Rosher RB. Tangling with the barriers to culture change: Creating a resident-centered nursing home environment. J Gerontol Nurs 2006;32:19-25.

49. Craig P, Dieppe P, Macintyre S, et al. Developing and evaluating complex interventions: The new Medical Research Council guidance. BMJ 2008;337:a1655.

50. Thomas WH. What Are Old People For? How Elders Will Save the World. VanderWyk \& Burnham; 2004.

51. Rabig J, Thomas W, Kane RA, et al. Radical redesign of nursing homes: applying the green house concept in Tupelo, Mississippi. Gerontologist 2006;46:533-539.

52. Idzerda L, Rader T, Tugwell P, et al. Can we decide which outcomes should be measured in every clinical trial? A scoping review of the existing conceptual frameworks and processes to develop core outcome sets. J Rheumatol 2014;41: 986-993.

53. de Boer B, Hamers JP, Beerens HC, et al. Living at the farm, innovative nursing home care for people with dementia: Study protocol of an observational longitudinal study. BMC Geriatr 2015;15:1-9.

54. Jones J, Hunter D. Consensus methods for medical and health services research. BMJ 1995;311:376-380.

55. Maayan N, Soares-Weiser K, Lee H. Respite care for people with dementia and their carers. Cochrane Database Syst Rev 2014;1:CD004396.

56. Sansoni J, Anderson KH, Varona LM, et al. Caregivers of Alzheimer's patients and factors influencing institutionalization of loved ones: Some considerations on existing literature. Ann Ig 2013;25:235-246.

57. Williams S. Family caregiver involvement for long-term care residents at the end of life. J Gerontol B Psychol Sci Med Sci 2012;67:595-604.

58. Schulz R, Rosen J, Klinger J, et al. Effects of a psychosocial intervention on caregivers of recently placed nursing home residents: A randomized controlled trial. Clin Gerontol 2014;37:347-367. 